\title{
DA MENAGEM E DA LESA-MAJESTADE
}

\section{NOTA PRELIMINAR}

Para clarear o assumpto, que me proponho tractar, direi ao leitor umas breves considerações, que concernem ao caso das pessoas envolvidas na materia, que aqui se versa.

E' de saber que, pelos acontecimentos politicos de Agosto ultimo, fomos honrados com a denuncia de rebeldes ou conspiradores. Nesse crime de rebellião contra o governo, a denuncia publica envolveu cento $e$ alguns nomes, a mór parte delles nomes de peso e de valor; e, por favor da fortuna ou boa vontade da policia, os nomes de Pennaforte Mendes e Raphael Correa foram apontados como os chefes da revolta.

Escusado é dizer que a justiça publica não provou o que affirmou. Entretanto, expedidos a esmo e ás resmas mandados de prisão preventiva, amigos entenderam que eu me devia asylar. Fiz isso. Que gratidão estou devendo, e deverei eterna, ao meu asylador, só Deus sabe. Revelar-lhe o nome seria uma vulgaridade sem outro resultado que ferir os melindres de uma sacratissima amizade. 
Desse asylo, pois, e após a soltura por habeascorpus de todos os presos politicos, occupei-me de mim e dirigi ao juiz da culpa uma petição de menagem, protestando defender os direitos de uma classe, antes que propriamente ventilar no debate judiciario os commodos de minha pessoa.

Essa petição mereceu da benevolencia dos entendidos alguns encomios e do juiz da causa um indeferimento formal, que aodiante veremos.

Como tractei a menagem com certa latitude, tomaram interesse alguns collegas e amigos de ver a petição reproduzida nas Revistas de Direito.

E, como coube ao meu amigo Dr. Pedro Lessa dirigir este anno a Revista da Faculdade, desejou que a materia tivesse assento neste livro, não já na primeira fórma de petição, mas modificada ou adaptada em dissertação. Eis, pois, a razão porque apparece aqui a menagem e a lesa-majestade: a substancia e quasi toda a fórma são aquillo mesmo que os jornaes já publicaram. 


\section{DA MENAGEM}

Ter por prisão sua casa ou sua cidade é ainda direito vigente. Não se diga que a Ordenação, Livro V, titulo I 20 e os posteriores alvarás estão, quanto a isso, derogados; pois a unica parte derogada é a que se refere aos fidalgos de solar, ou assentados nos livros de nobreza, aos cavalleiros fidalgos ou confirmados, e aos cavalleiros das ordens militares, visto que só estes fundavam seus privilegios em nascimento, fóros de nobreza, ordens honorificas. $\mathrm{O}$ art. $72, \S 2$, da Constituição da Republica, diz:

«A Republica não admitte privilegio de nascimento, desconhece os fóros de nobreza e extingue as ordens honorificas existentes e todas as suas prerogativas e regalias, bem como os titulos nobiliarchicos e de Conselho.»

A Constituição da Republica supprimio umas classes de cidadãos que gozavam de umas tantas prero- 
gativas. Ora, é claro que, não existindo mais os sujeitos em quem essas regalias se radicavam, ellas desvaneceram.

Não foi tanto que se houvesse revogado, em parte, a Ordenação, mas foi propriamente que desappareceu uma porção daquelles sujeitos, para quem dicta Ordenação legislava.

Como quer que se encare pela theoria o nosso assumpto, na pratica é verdade que o citado texto da Constituição nada diz relativamente aos officiaes militares, aos desembargadores, aos doctores em leis, em canones, ou medicina, e, portanto, está clarissima a intenção de manter em vigor a Ordenação, na parte que não foi attingida pela disposição constitucional.

$\mathrm{E}^{\prime}$ principio corrente de hermeneutica que, referindo-se a lei nova a uma enumeração contida na lei antiga, quiz abranger a parte que enumerou e não a parte que deixou de enumerar.

Afim, porém, de dar a esta materia uma explanação que esteja na altura do assumpto, pondo ao lado a pequenez pessoal do réo, que foi occasião e motivo desta indagação juridica, pede o auctor venia para discorrer sobre o caso, encarando a materia no que concerne ao simples advogado, no que toca aos doctores e no que interessa aos professores ou lentes.

Dissemos já que o texto da Constituição republicana em nada obsta a vigencia da Ordenação, Livro $\mathrm{V}$, titulo I 20. Dizemos agora que não conhecemos texto algum, nem tão pouco algum jurisconsulto, que auctorise affirmar que as regalias ou prerogativas das 
profissões scientificas foram perimidas pela Constituição do Imperio.

Neste assumpto, como em quasi todos os institutos da vida juridica, o Direito Regio descendeu do Direito Commum ou Romano.

Pelo Direito Regio, a nobreza, pode-se affirmar, provinha de quatro fontes: sciencia, milicia, emprego $e$ privilegio propriánente dicto.

A ultima era emanada da graça ou favor do principe, ou então herdada, mas as outras eram conquistadas ou adquiridas. Nós aqui só versaremos as questões que disserem com a nobreza emanada da sciencia.

A Constituição do Imperio, art. I 79, § XVI, assim dispõe:

«Ficam abolidos todos os privilegios que não forem essencial e inteiramente ligados aos cargos por utilidade publica.»

A expressão privilegios aqui é tomada na significação de immunidades, ou prerogativas, conforme se pode ver, por exemplo, nas annotações de Rodrigues, Constituição Analysada por um jurisconsulto, edição de I863, Laemmert, Rio de Janeiro.

Nem pode haver quem duvide ser esse o sentido da Constituição Imperial.

Quem duvidasse veria claro qual foi a significação em que usou aquella palavra o legislador constituinte, lendo o $\S 48$ de Coelho DA Rocha, na sua monumental obra-Direito Civil: chamam-se privilegios os direitos especiaes que as leis concedem em favor de certas pessoas ou cousas, como excepção ou dispensa da lei geral. 
Visivelmente, a essa significação se liga e, de certo modo, se contrapõe a outra, na qual a palavra privilegio propriamente dicto é o direito estabelecido em prol de uma so pessoa, como o dos novos inventos. $\mathrm{E}$ tão a pelo vem aqui estas considerações que, a este mesmo proposito, cita CoElho DA Rocha a Constituição Portugueza, art. I 45, § I 5, onde se dispõe, em relação a privilegios, a mesma doctrina, pelas mesmas palavras que a Constituição do Imperio.

Cargos, que são?

Os nossos antepassados, elaborando a Constituição de I824, haviąm necessariamente usar as expressões em voga. A palavra cargo, como em geral todas as palavras em todos os idiomas, não tem uma só, mas varias significações.

Oiçamos Pereira e Souza dos mais auctorisados jurisconsultos:

"No uso e phrase ordinaria, cargo confunde-se com officio. Differem em que o nome de cargo se dá propriamente ás funcções publicas ou particulares, que sempre se reputaram onerosas, como curatelas, tutelas, empregos de policia e municipaes, etc., etc.

"As leis romanas lhes chamavam munera publica, quasi onera.

"Os officios e dignidades, pelo contrario, eram designados pela palavra honores, e differem dos cargos em attribuirem ás pessoas nelles providas uma porção do poder publico, a que está annexa uma certa honra, privilegios de grau, preeminencia, pompa exterior ou cousa semelhante.» Diccionario furidico, verbo cargo. 
Ve-se pois, que, no entender desse notavel jurista, a palavra cargo é mais lata que officio ou dignidade. Podemos dizer que cargo é genero de investidura, e officio ou dignidade é especie.

Quer consideremos de um, quer de outro modo, havemos de asseverar á luz da razão que as investiduras conquistadas pelos advogados, pelos doctores e pelos professores ou lentes, são cargos.

Não devendo nós, porem, dar um so passo neste pouco trilhado terreno sem roborar nossas affirmações com a auctoridade dos mestres, citemos por primeiro a Foão Carvalho, em sua obra latina, Ad. Cap. Raynaldus, parte $\mathrm{I}^{\mathrm{a}}$, n. 264 e seguintes, onde, amplamente dissertando da nobreza grangeada pela sciencia, fala do advogado, lente ou medico, chamando-lhes a profissão munus, officium, dignitas, honor.

O mesmo modo de comprehender o caso tem Phebo, no seu repertorio de Decisoes e Arestos, a cada passo.

Ahi temos dilucidada a significação dos vocabulos privilegios e cargos: desçamos a tratar das tres classes de pessoas que fazem ao nosso intento, e seja a primeira a classe dos advogados.

\section{III}

Advogados. Que a sciencia é só por si a mais alta nobreza que ainda houve, só ignoram os mais rusticos ignorantes.

O citado, Carvalho na citada obra, faz uma larga dissertação, rica de erudição, sobre o merito do homem scientista. Invoca em seu prol textos do Ecclesiastes, dos Proverbios, de Aristoteles, de Seneca, e innu- 
meros do Direito Romano, nos' quaes se fazem as mais exaltadas allusões aos homens de sciencia pelo esplendor, dignidade e beneficios que trazem á Republica.

Ulpiano, diz elle, foi tratado e havido por nobilissimo, por causa de sua jurispericia; os lettrados em geral são reputados estrellas do firmamento: a nobreza verdadeira é a que outorga a sciencia, preferivel a do sangue e da fortuna. E, no meio das mais variadas citações de escriptores de varios tempos e paizes, extende-se o citado escriptor sobre o merito dos advogados e sobre a sua necessidade na ordem do mundo, fazendo especial menção dos textos do Codigo, De Adv. div. jud., em que são os advogados EQUIPARADOS AOS MILITARES COM uS mais subidos encarecimentos.

Do Direito Regio consigna Phebo, em sua retrocitada obra, innumeros julgados em que aos advogados se extende a prerogativa de menagem, ainda que sejam graduados em Licenciados ou Bachareis. Phebo, Aresto - LVIII, vol, I. E accrescenta este jurisconsulto que tal maneira de julgar, ampliando a palavra doctores a comprehender os advogados, observa-se inviolavelmente -inviolabiliter observatur.

\section{IV}

Doctores. Estes estão comprehendidos expressamente na Ord., Liv, V.. tit. I 20. E se entendem não so os graduados em canones ou direito civil, como os que o forem em theologia. E' de notar que os simples sacerdotes são reputados nobres para gozarem das vantagens ou prerogativas da nobreza, bem que não tenham uma das graduações das lettras profanas ou sagradas. Phebo, obra citada, assim o traz jul- 
gado. Aresto, I 8 I, vol. II. E cita textos dos commentadores, em que o sacerdote é EQUIPARADO AO SOLDADO.

Nem de outro modo se devia reputar uma classe desta sorte respeitavel, maxime em um paiz em que a crença catholica era de toda a nação, e n'uma epoca em que ao clero pertenciam notabilidades, que adornavam as cadeiras das academias.

Professores. Os privilegios da nobreza, diz o citado Carvalho, se extendem aos professores, quer se trate dos lentes das Universidades, quer se trate dos mestres de artes. Esta expressão de sabor antigo não corresponde ao conceito moderno da palavra artes. Os nossos maiores chamavam mestres d'arte aos professores dos cursos de lettras, como o eram a Grammatica, a Rhetorica, a Philosophia, a Geometria. CARvalho, ob. cit., n. 283 e seg. Phebo, dec. i6 I, ns. I I e I 2, vol. II.

\section{VI}

Cargos publicos. Comquanto a investidura scientifica ou profissional que conquistam os advogados, doctores e professores seja mais de vantagem individual, não ha negar as vantagens publicas que frue a sociedade dos serviços daquellas pessoas.

Dest'arte pode-se dizer que exercitam tambem funcções publicas, bem que não sejam funccionarios publicos no rigoroso sentido do Direito Administrativo.

Os advogados estão por officio obrigados a defender clientes no civil e no crime. 
Os juizes podem-n'os compellir a assistir com seu patrocinio, não so aos menores, senão tambem aos miseraveis, tanto no fôro civil, como no fôro criminal; sendo, aliás, certo que no fôro criminal, para serem compellidos a defender, basta o simples facto de apparecer o reo a julgamento desacompanhado de potrono, nada importando si é ou não pessoa miseravel.

O juramento, formalidade solemne que hoje empallidece em compromisso, o juramento que prestam os bachareis e doctores na occasião da investidura, bem affirma a funç̧ão publica nobilissima a que são convidados pela lei, a qual com antecipação e encarecimento implora o patrocinio delles em prol das viuvas e dos orphams.

Os doctores em medicina, quer na sua arte cirurgica, ou pharmaceutica, quer na prestantissima sciencia de penetrar em os seios reconditos do corpo doente e conhecer tambem os muitos segredos d'alma, bem merecem as palavras de respeitoso amor com que as sagradas Lettras aconselham a doente humanidade: Honora medicum propter infirmitatem. E'comezinha a obrigação, que todos sabemos, impostas aos medicos pelas leis de policia e de processo, para que acudam aos corpos de delicto, ás autopsias, aos exames de sanidade, a mil pequenas necessidades, ordinariamente subitas e inadiaveis, de modo que infinitos e inapreciaveis serviços são prestados em puro proveito da ordem e bem publicos.

As enfermidades são tão impossiveis de extinguir como as contendas dos interesses.

Naquellas, mais se ve a fatalidade da natureza irresponsavel; nestas, mais se percebe 0 influxo da liberdade.

E' certo, porem, que a fatalidade cega e a liberdade avisada, ambas no exercicio de suas forças de 
incoercivel expansão, reclamam e hão de reclamar, sem possivel detença, a intervenção dos homens superiores á massa commum, para dirigirem seus negocios, ou para proverem á sua saúde.

Estas duas classes de pessoas, mais os professores, são alicerces da civilisação. O bem publico, como tira proveito dos advogados e dos medicos, tira das liç̧ões dos lentes um dos mais salutares beneficios.

Ainda quando elles não sejam publicos funccionarios, a nobilissima profissão de educar e illustrar a mocidade torna-os benemeritos entre todos os povos cultos. Quando são empregados publicos, propriamente dictos, quaesquer prerogativas que exornem o cargo que exercitam, redundam em lustre para a propria sociedade.

Eis, portanto, que, si os professores ou lentes, no rigor da nossa organisação administrativa ou governamental, são homens investidos de cargo publico, os advogados e doctores tambem exercem os seus cargos, praticando nelles certas funcções publicas.

\section{VII}

Utilidade publica. O privilegio ou prerogativa da menagem é um bem publico?

A menagem é uma utilidade estatuida para bem particular tão sómente? Ou liga-se aos cargos de advogados, doctores ou lentes, por utilidade publica?

A todas estas perguntas, respondemos em breves ponderações. Não ha duvidar que a menagem foi instituida como sendo de publica utilidade.

Assim a consideraram os povos cultos, assim falla nos textus dos nossos tratados de direito a sabedoria dos antepassados. 
A menagem foi excogitada e havida como um poder coercivo que não desdoira os accusados e de proposito para não desdoirar nem molestar as pessoas gradas.

Tal instituto, si tinha em si, como tem, reaes vantagens para os individuos, foi caracterisado como privilegio em prol do bem geral da sociedade.

Phebo, Decis. 48, vol. II, expõe com a costumada clareza esta materia, trazendo a publico um julgado da Supplicação.

Um certo varão nobre, de nome Francisco Paes, renunciou ás mãos de um credor o privilegio de sua nobreza para o effeito de poder ser encarcerado, si não pagasse a tempo e hora o mutuo que havia contrahido.

Levado o caso á Supplicação, decidio que tal privilegio ninguem podia renunciar, que não era valida a renuncia.

E diz o texto: «Porque o privilegio, concedido a respeito de uma qualidade inherente á pessoa e por contemplação a uma classe, não é licito renunciar».

E mais adiante frisa o caso de um advogado que, não estando sujeito ao carcere pela investidura de nobre, a que foi levantado pelo seu cargo scientifico, si renunciar ao officio de advogar para valer como renuncia da nobreza, não tenha validade este acto. Mais frizante, si quizermos, depara-se um trecho do jurisconsulto BĖnedicto Egydio, no tratado latino Dos Advogados, cap. 4, onde se leem entre vasta materia aproveitosa, estas palavras que ferem ao nosso ponto: "Não podem os advogados renunciar ao direito de não ser encarcerados, porque tal privilegio não 
foi concedido aos advogados em proveito particular, mas por causa da dignidade das lettras e profissão litteraria, a qual pelo carcere ficaria melindrada».

No conceito dos jurisconsultos nada obsta á doutrina supra-exposta aquella conhecida e vulgarissima regra" de quem quer, póde renunciar ao seu privilegio. Esta regra padece limitação, observa PHEBo, e é quando o privilegio foi instituido in favorem publicum, isto é, em bem e utilidade publica.

«E, na verdade, quando em alguma disposição legal concorrem ao mesmo tempo o favor ou proveito publico e o privado, os quaes admittem separação, vale a renuncia naquillo que concerne ao bem particular e não vale no que interessa ao favor publico».

Phebo, Decis. 145, vol. II.

Mais apropriados ao nosso caso ninguem acharia outros textos. São os julgados dos tribunaes superiores, commentados por insignes jurisconsultos, que, affirmam a feição caracteristica com que se introduziram no Direito Regio as immunidades do carcere. Assim praticando, como praticaram os nossos maiores, nada mais fizeram do que perpetuar nos textos da lei escripta aquillo que é lei natural, gravada no coração de um povo culto. Respeito, consideração, estima e uma grata admiração pelos homens eminentes no saber, são tributos que sabemos quotidianos entre gente civilisada. Estimulo civilisador é por sem duvida realçar a propria nação o merecimento dos seus homens lettrados.

$\mathrm{Si}$ bem ponderarmos, na propria Ord. do liv. $\mathrm{V}$ tit. I $20, \S \mathrm{I}$, encontramos o mais formal argumento de que a menagem era tida pelos legisladores de 1603 como prerogativa que só visava o bem publico. 
O nobre que se mostrava renitente em dar a homenagem que o juiz do crime the mandava, não era por isso encarcerado, nem aggravava sua situação.

Manda o citado $\S$ que o juiz imponha a homenagem, ou o tenha preso sobre ella. «E quando alguma pessoa não quizer dar a homenagem, todavia o haverão por preso sobre ella, e far-se-á disso acto (auto), e valerá a prisão como que a déra: e não a cumprindo, lhe será havido por quebrada.»

\section{VIII}

$O$ livro $V$ revogado? - Não consta que haja jurisconsulto que opine abolido o privilegio da menagem; e, como o titulo i 20 desse Livro é o assento primordial desse privilegio, tratemos de examinar a procedencia da opinião que cuida revogado o Livro V.

A lei brazileira que adoptou para nós o Direito Regio é de 20 de Outubro de 1823 , carta de Lei, emanada de Pedro I, subscripta por Carneiro de Campos, mas obra já da Assembléa Constituinte. No art. I. se acceitam, como regras do nosso Direito, as Ordenaç̃os, leis, regimentos, alvarás, decretos e resoluções, promulgadas pelos Reis de Portugal. Ora, não é so o tit. I 20 do Liv. V que contém a materia da menagem. A este modo de custodia não só se referem outras Ordenações, como um numero consideravel de disposições extravagantes, que convem memorar:

I) Alvará de 7 de Junho de 1.755 , que deu tal privilegio ás pessôas da companhia do Pará;

2) Alvará de io de Setembro de I756, § 39, aos que entrassem com 6.000 cruzadus de acções na Companhia das Vinhas do Alto Douro; 
3) Alvará de 16 de Dezembro de I 756, cap. I 8 , ás pessoas da Junta do Commercio, emquanto servirem, e ao Provedor e Vice-Provedor ainda depois;

4) Alvará de I 3 de Agosto de I 759, § 43, ás pessoas da Companhia de Pernambuco;

5) Resol. de 26 de Janeiro de 1764 e Dec. de I4 de Julho de I 775 , aos professores de latim.

De modo que, si o livro $\mathrm{V}$ perimio-se de todo, não se salvando delle nem as regras de processo, nem outras disposições extranhas aos crimes e suas penas, não se perdeu com elle a menagem, porque esse instituto, incorporado como está no. Direito Regio, consta expresso e bem patente em disposições legislativas posteriores ao Cod. Philippino.

Mas, porque admittiriamos nós que está revogado o Livro V? Seria pela lettra, ou pelo espirito do Cod. Crim. de I 830 ?

Não, nem por uma, nem por outro. Esse codigo, que legislou para os crimes e para as penas, não legislou sobre prerogativas de ninguem, nem sobre mo dos de prender accusados.

Tendo revogado esse codigo todas as disposições em contrario, apenas perimio tudo que é materia de penas e de crimes, assumpto este que principalmente constitue o Liv. V, mas não o constituia exclusivamente. $\mathrm{E}$ é porque quasi tudo que constituia a materia criminal do Direito Regio se achàva consolidada no Liv. V, que constumamos dizer vulgarmente que o Cod. Crim. revogou aquelle livro das Ordenaçoes.

Esta phrase, assim enunciada, contém uma verdade, mas não a verdade inteira. A verdade inteira se enunciaria, se dissessemos: $O$ Cod. Crim. revogou o Livro $V$ em tudo que se refere a crimes e penas. 
$\mathrm{E}$ os privilegios da prisão de menagem, bem que mais pertençam á ordem das relações criminaes, do que á ordem das relações civis, todavia não são, no rigor do termo, materia criminal, que devesse estar contida e legislada no Cod. de i 830.

A menagem se applica não só nos casos de prisão criminal, mas tambem nos casos de prisão civil. Entre os casos de prisão civil, havia no Direito Regio a que era occasionada por dividas, por custas e por deposito não restituido, etc.

E no Direito Patrio, comquanto hajam diminuido as causas da prisão civil, todavia ainda temos a do deposito, do penhor, da arrematação, do perigo de fuga; e tanto esta materia é de alçada ou esphera das relações civis, que nada dispõem sobre ella as leis criminaes. No Cod. Proc. a disposição que mantinha a prisão por custas, não pagas em vinte e quatro horas, vem justamente no art. Io da Disposição Provisoria que rege materia de justiça civil.

Estas considerações vão feitas para accentuar que, se o Cod. Criminal houvesse regulado a materia das prisões, não o teria feito senão no que concerne á ordem criminal, nunca no que interessa ás prisões de ordem civil.

Mas, nem o Cod. Criminal, nem o do Processo, que é datado em Novembro de 1832, nem a lei de 3 de Dezembro de 184 I, nem o Regulamento I 20 de I842, nem a Reforma Judiciaria de I871, nada dispõem que contrarie o systema do Direito Regio, que passou para o Direito Brazileiro.

Apenas o Reg. I 20, tratando de inspecção e economia das prisões ou carceres, recommenda ás auctoridades policiaes aquillo que vem desde os romanos altamente legislado, a saber: separação das mulheres, 
separação dos menores, separação dos simples detidos, separação dos recrutas, attenção á qualidade dos detidos e outras providencias de asseio e hygiene, aliás tambem reguladas em muitas disposições do Codigo Justiniano.

A complexa materia, em conclusão, que se comprehende na geral expressão de coaç̧ão á liberdade, materia que se compõe de preceitos e direitos de ordem civil, preceitos e direitos de ordem criminal, preceitos e direitos de ordern commercial, de ordem administrativa, de ordem municipal, de ordem judiciaria e de ordem policial, não está regulada no Cod. Criminal, nem no Cod. do Processo, nem nas leis posteriores, que supra citamos.

Ao contrario, tanto nesses dois codigos, como nas leis posteriores, o espirito que domina é suppôr sempre conhecidas e assentadas as regras sobre esse assumpto. Quando nesses padrões dos nossos direitos e garantias ha referencia á prisão, ao constrangimento pessoal, á privação do direito de locomoção, a linguagem dos textos é tal que suppõe sabido e certo o direito relativo a esta ordem de relações.

A perempção do Liv. V, portanto, não pode e não deve ser entendida senão naquillo que estrictamente se relaciona com a determinação das figuras dos crimes e das suas respectivas penas.

Tudo mais não se perimio, porque não contradiz as disposições do direito moderno; e nesse sentido deve ser entendida a nota de Candido Mendes sobre o caso. O proprio Alves Branco, auctor do Cod. do Proc., occupando tres annos depois o ministerio da Justiça, expediu o Aviso de 22 de Julho, I 835, declarando que nos actos do processo criminal não regulados pelo Cod. de Proc., subsistem as Ord. do Liv. 
$\mathrm{V}$ e toda a legislação anterior ao Cod. E' de notar que esse Aviso, firmando tal doctrina, determinava exactamente a applicação de uma Ord. do Liv. V a um acto de processo. Que melhor interprete á hypothese que Alves Branco?

Quando Candido Mendes se refere ao facto de não ter sido applicada a Ordenação do L. V., tit. I 20 , não quer dizer que ella tenha sido abrogada, tanto que allude á implicita derogação operada pela Const. do Imperio, aos privilegios não ligados aos cargos por utilidade publica. O proprio C. Mendes nola que essa Ord. tem sido applicada aos militares e ás pessoas a elles equiparadas.

Candido Mendes jámais disse que o $\mathrm{L} . \mathrm{V}$ das Ords. estava todo revogado. Ao contrario, affirmou que esse livro se acha QUASI ToDo revogado. O quasi é tudo ahi para a nossa argumentação.

\section{IX}

Revogação de Privilegios - O systema, a indole, o espirito das leis, esse quê impalpavel, invisivel, mas potente, que informa e vivifica o direito e que incute o passado no presente e o presente no futuro, elaborando paulatinamente as mutações, sem quebrar, todivia, os elos da cadeia que nos ata aos Lusitanos e que vincula os Iberos a Justiniano, não permitte que nós affirmemos quebrados e supprimidos uns antiquissimos privilegios, sem que leis expressas os houvessem derogado.

E na verdade, como é pelo nosso direito que se revogam os privilegios?

Dil-o o eminente PheBo: «Entre as demais prerogativas que tem o privilegio incluso no corpo do 
direito, é esta:--nunca se ha por derogado sem especial menção feita na nova lei, ainda que a nova lei traga nas suas disposições a clausula:-não obstante qualquer privilegio. Porquanto esta clausula ou outra semelhante não comprehende os privilegios incorporados no direito ou inclusos no systema das leis.»

Phebo, vol. II, Dec. 145, ns. 4 e 5 .

Não é menos claro e positivo o celebre Pedro Barbosa, nos Commentarios ao Titulo-de soluto matrimonio, Part. I, ns. I I e I 2.

«A clausula non obstantibus privilegiis se entende sufficiente para derogar os privilegios extraordinarios.

Todavia, tal clausula não attinge os privilegios incorporados no direito, a não ser teita delles especial menção, e a razão da differença consiste em que, privilegio incorporado no direito, em relação aos privilegios extraordinarios, mais parece diveito commum que privilegio, e por isso, na derogaşão dos privilegios, nunca se entende derogado aquelle que está incorporado no direito, pois este de certo modo imita ou assume a natureza de direito commum.»

Quer Phebo, quer Pedro Barbosa, citam consideravel numero de commentadores do Direito Romano e do Direito Regio, por onde se ve que, si os legisladores brasileiros, influenciados do espirito e systema das leis lusitanas, quizessem abolir os privilegios da menagem, precisavam, necessariamente, fazer delles especial menção.

Si o Codigo Criminal ou do Processo, ou as leis posteriores que formam o corpo do Direito Processual, si qualquer desses monumentos de saber contivesse algum artigo mais ou menos nestes termos-Ficam revogados todos os privilegios em materia criminal-, ainda assim o privilegio da menagem não ficava abo- 
lido, porque é um instituto longamente e esparsamente incorporado no systema do nosso Direito, e que nunca se entenderia perempto, senão quando fosse ferido de frente pela lei revogadora.

\section{$\mathrm{X}$}

$A$ menagem e a republica-O principio da menagem não é invenção dos jurisconsultos de Philippe II, consagrada nas Ordenações de r603. Já vem esse liberal instituto consagrado expressamente no Livro $\mathrm{V}$, Tit. 94, das Ordenações Affonsinas, e depois no Liv. V, Tit. 67, das Ords. Manuelinas, em cujos textos já se lê menagem em vez de homenagem, palavras equipollentes, não sendo aquella mais do que abreviação ou corruptela desta.

Podemos ir a mais. Não foi o primeiro Affonso $\mathrm{V}$, o Africano, quem se lembrou por seus jurisconsultos de consagrar nos textos uma disposição de alta relevancia. O primeiro texto é de Ulpiano, que flores. ceu e foi assassinado em o principio do seculo $3 .^{\circ}$ da era christã.

«A respeito da custodia dos réos, o pro-consul costuma decidir si o accusado deve ser encarcerado, si deve ser entregue a um soldacio, si deve ser confiado a fiadores, ou si deve ser deixado sobre si. Isto depende, ou da qualidade do crime, ou do cargo que occupa o accusado, ou da sua fortuna, ou da sua probidade, ou finalmente da sua posição social.» (Dig. de Cust. et exhib. reor.)

Eis ahi a sabedoria romana dando o criterio ao pro-consul numa sociedade culta, mas pagã, a qual, si tendia politicamente para seu occaso, é certo que nas suas relações sociaes ainda não tinha experimentado a 
influencia do christianismo. Mas, ainda não é tudo. No tempo do maior resplandor litterario da Republica Romana, quando a palavra opulenta de Cicero enchia o Senado e o seu patriotismo salvava Roma de cahir ás mãos de Catilina, conta Sallustio que o Senado auctorisou o consul, descobertos os conjurados, a entregar em prisão livre cada conjurado a uma pessoa grada, tanto que ao senador Julio Cesar coube em guarda o conspirador Statilio.

Eis o exemplo da Republica Romana: os conjurados de Catilina entregues cada um a um amigo, por ordem do Senado!! (Sallus., Catil., n. 47).

A detenção ou custodia preventiva, consistindo na permanencia obrigada em determinada cidade, villa, logar ou casa, é nas legislações modernas uma instituição ordinaria e commum e não um privilegio.

Sem nos referirmos á legislação da Belgica, a mais liberal da Europa; sem nos referirmos ás leis inglezas, que difficilmente conservam alguem em prisão; basta attendermos para a legislação italiana, na qual muito expressamente se determina que o juiz instructor pode, durante o processo da instruç̧ão, em vez de prender, determinar a permanencia em certo logar, a obrigação do comparecimento diario, e pode ainda cassar o mandado de prisão preventiva, qualquer que seja o estado da causa.

Dizem que a Republica Brasileira é uma democracia pura: si assim é, a tendencia devia ser ampliar a menagem, porque isso não seria outra coisa que desenvolver ou cultivar um instituto liberal. Os povos que caminham para diante tendem a converter um tal privilegio em direito commum.

Tanto não é contraria a menagem á indole republicana, que, nestes ultimos tempos, não passa talvez 
um só anno sem que se realisem algumas prisões desta especie na classe dos militares.

Si a milicia, sem extranheza alguma, goza dessas prerogativas, sendo em toda hypothese muito mais rigorosas as leis da vida militar, muito mais cerrados os vinculos da disciplina, não ha para que se descontinue ás pessoas da ordem civil uma praxe liberal instituida ja pela civilisação pagã e sanccionada pela sabedoria de tantos seculos christãos. 


\section{CONCLUSÃO}

Si parece evidente que se não deve negar menagem ao advogado; si não se deve negar aos doctores em geral, a fortiori não se deve negar aos professores de Direito, como quem são pelas leis notavelmente accumulados de distinções. Semı indagarmos agora as razões dos factos, é certo que, si o Direito Regio exornou a classe dos lentes com graduações honorificàs, o Direito Imperial ainda accrescentou:

A lei de I I de Agosto de I827, art. 3, diz que os lentes gozam das mesmas honras dos Desembargadores; os Estatutos do Visconde da Cachoeira estabelecem, no Cap. XVIII, $\S$ r.o, que os professores do Curso Juridico serão contemplados com todas as honras e prerogativas de que gozam os da Universidade de Coimbra. Os Estatutos de 28 de Abril de 1854 , art. I 58 , dizem :

"Os lentes, quer cathedraticos, quer substitutos, terão as honvas de Desembargador; o Regulamento de 
I9 de Abril de 1879, art. 20, § i 8, exprime-se: "Os lentes cathedraticos e substitutos gozarão das honvas $e$ privilegios de Desembargador».

Eis ahi a materia que constituio a petição da menagem, datada em 20 de Outubro, e offerecida ao juiz federal, instructor da culpa aos iniciados no crime de rebellião. Deu elle, sem parecer do promotor da justiça publica, o seguinte despacho:

«Indefiro a petição de fl.

«A Ord. liv. V, tit. I 20 , em que «o peticionario funda o seu requeri«mento, não tem mais applicação desde «a promulgação da Const. Politica de «I 824, que pelo art. I 79, § XVI, abolio «todos os privilegios que não estivessem «essencial e intimamente ligados aos «cargos, por utilidade publica, e, com «sobrada razão, pela Const. Politica de «I $89 \mathrm{I}$, art. 72, $\$ 2$, que proclamando «ainda uma vez a principio da igual«dade de todos perante a lei, impugna "privilegios de raça, casta ou classe, «porque a todos nivela e irmana $O$ «direito. (Barbalho, Const. Fed. Comm. «ao art. 72; C. Mendes. Cod. Philipp. «n. á Ord. livr. V. tit I 20).

«E essa é a constante lição de «todos os nossos tractadistas, por esta«rem revogadas as leis do antigo regi«men, no que explicita ou implicita«mente for contrario ao systema de «governo firmado pela Const. e nos 
«principios nella consagrados. (art. 83 «Const. Fed.)

«E quando se pudesse invocar o «obsoleto privilegio da Ord. liv. V, tit. « I 20 princ., ainda assim a disposição «invocida não aproveitaria ao denun«ciado, pois a menagem não se ampliava «aos criminosos incursos nas penas de «morte natural ou civil, e essas eram as «penas edictadas para os crimes anti"gamente de lesa-macrestade, entre os «quaes se inclue o modernamente cha «mado crime de conspiração.

«P e Int. S. P. 27 out. 1902.

Aquino e Castro 


\section{DA LESA-MAJESTADE}

Em replica ao despacho do juiz federal, fiz uma petição que não chegou a ser apresentada.

Asylado como estava, não podia ser dada a replica em continente; de modo que, quando ia ser apresentada a nova petição, $j a$ os jornaes apontavam a audiencia em que se ia publicado o despacho de pronuncia. Como, porem, não fosse pronunciado nenhum dos indiciados, baldou-se a opportunidade da replica. Não se balda, porém, a opportunidade de um estudo juridico.

Eis porque damos em seguida a materia da segunda petição, que tinha por objecto o instituto da lesa-magestade.

\section{I}

A Ord.. Livro V, tit. I 20, deu por criterio aos juizes, para darem ou negarem menagem, a pena do delicto e a qualidade do deliquente. Deliquente a que se deve applicar pena de morte natural, ou pena de morte civil, é excluido das prerogativas da mena- 
gem. Ora, em materia criminal, não $\in$ licito aos juizes induzir aggravamento algum; ao contrario, é obrigação ampliar as disposições que favorecem os accusados, consoante o principio de equidade, inscripto nos tratados: odiosa restringenda, favorabilia amplianda. E ainda mais: não havendo disposição alguma que dê ao juiz outro criterio, que não seja o enunciado no tit. I 2O, não é licito inventar criterio novo, fundado na pretensa equipollencia entre a lesa magestade das monarchias absolutas e as conspirações quasi quotidianas das Republicas mais ou menos democraticas.

O illustrado juiz achou que é ja obsoleta a Ord., L. V, tit. I 20; mas não a tem, nem pode ter, por abrogada; porem affirmou que, embora vigorasse, ao impetrante ella não aproveitaria, como a rebelde ou conspirador, visto que esse crime é correspondente ao de lesa-majestade, e ao de lesa-majestade era negada menagem.

A lesa-majestade era punida de morte cruel com a infamia. E o Cod. Crim. de 1830 acabou com as penas crueis e acabou com a infamia, não consentindo que passasse a pena da pessoa do deliquente. Isto posto, raciocinemos.

\section{II}

Em consequencia ao criterio que firmamos em o numero antecedente, criterio expresso no citado tit. I 20, 0 juiz nada mais tinha que fazer, dada a hypothese de vigorar o tit. citado, sinão verificar as qualidades do impetrante e a pena do crime em o qual elle se achava indiciado. As qualidades do requerente, sendo notorias, não se faziam mister provadas, bastava serem allegadas, segundo a lição dos mestres: Notorium allegandum esse. Mascardo, De prob. Conc. ilio. 
A qualidade da pena, essa, o juiz ja de ha muito tinha verificada e certa, desde quando acceitou sem emenda a denuncia do procurador da Justiça, que concluiu pela reclusão de seis annos.

Certa a qualidade do deliquente, certa a pena, a conclusão da logica juridica, que nem sempre condiz com a logica politica, seria a concessão da menagem.

Verdade é que o Direito Regio tem disposições especiaes extravagantes, posteriores á codificação philippina, em que se assenta negar menagem a determinados crimes. Taes são os crimes de conversão escandalosa nos mosteiros de freiras; o crime de duello, que tambem se chamava desafio; o crime de estorvar a extracção de trigo das ilhas para Lisbôa, e o de captivar os indios no Brasil.

Aqui, nestas disposiçoes, olhou o rei para a natureza dos delictos e negou-lhes menagem sem attenção ao criterio da pena. Taes alvarás, longe de infirmarem, confirmam que o criterio está na pena e não em a natureza do crime.

Entretanto, com a deferencia que se deve á toga do magistrado, diremos que não procede a inferencia que fez o meritissimo juiz, quando achou que, negando o Direito Regio menagem á lesa-majestade, devera elle negar menagem aos indiciados em crime de conspiração, porque, affirma elle, a conspiração ou rebellião de hoje é de natureza daquelles que outr'ora se capitulavam sob o nome de lesa-majestade! Explanemos $o$ assumpto.

\section{III}

Os casos de lesa-majestade, materia de maior revelancia no Direito Publico Regio, vêm enumerados na Ordenação, Livro V. tit. 6. Com a clareza ás vezes 
prolixa com que os antigos jurisconsultos expendiam a doutrina, o proemio da citada Ordenação define assim o nosso caso:

«Lesa-majestade quer dizer traição «commettida contra a pessoa do Rei, «ou seu Stado Real. »

Deste principio parte a lei para enumerar os oito casos em que se commette a traição; e em todos elles, é muito para ver como o legislador quiz que fosse indispensavel no crime a intenção de attentar contra a pessoa e auctoridade do monarcha, ou, melhor, contra a majestade delle. E si ainda, por maior estudo, quizessemos perquirir os casos crimes de lesa-majestade, chamados no Codigo Philippino-capitulos de segunda cabeça, notados em o n. 22 e seguintes deste mesmo titulo, não encontrariamos ahi coisa que se pareça com a conspiração ou rebellião, tratadá em as nossas leis criminaes e de processo. E a razão é obvia para quem inquire ou indaga as coisas pelas suas causas: rerum cognoscere causas.

\section{IV}

A majestade é um instituto obsoleto; mais do que isso, extincto em o nosso direito publico, ainda considerado sob o Imperio.

A concepção do Direito Philippino era que, apezar das Côrtes, que já então se convocavam, a majestade do monarcha, isto é, todos os direitos e prerogativas da soberania, coadunados na pessoa do imperante, nada tinha de investidura popular, não tinha que ver com a vontade do povo, nenhuma parcella do poder publico derivava dos subditos ou vassallos. Esta, precisamente esta, era a concepção philosophica e respeitavel dos sabios antepassados. Baste-nos por agora 


\section{$-43-$}

a certeza dos factos: é indubitavel que nós não temos mais essá figura juridica, denominada majestade, figura gerada nas penumbras da civilisação, crescida ao calor das virtudes dos soberànos, enaltecida e arraigada no seio das massas pela gratidão dos povos, sanccionada pela opinião dos philosophos, como um bem que era para as sociedades. Essa figura, depois de formada e feita segundo as feições do Direito Philippino, atravessou os seculos em revezes de grandeza e ignominias, como tudo que é humano; e, sem estorvar a carreira da civilisação, ella se foi apagando aos poucos, até que desvaneceu de todo.

Não foi o 7 de Setembro de 1822, nem a Const. Imperial de I 824 , que extinguiu a majestade. Mas era porque de facto ja ella estava extincta que o Septe de Setembro se fez assim e a Const. Imperial proclamou que os poderes politicos são delegações da nação. Aquillo que representar real e verdadeiramente a necessidade de um povo, aquillo que, sob a balança da Justiça, for vital para uma nação, isso é o seu Direito.

Ha uma necessidade intrinseca, absolutamente indispensavel em todos os tempos, em todos os povos: é o principio da Justiça, que por isso é eterno e immutavel. Ha, porem, necessidades da vida exterior, variaveis segundo os tempos e os logares: são as relações do Direito mudavel, do Direito que acompanha o progredir e o regredir das nações.

E' certo que os commentadores do Direito Romano enxergam os principios ou origens da lesa-majestade nos estatutos de Romulo; depois, na Taboa IX, cap. 7, da Lei Decemviral, e dahi percorrem as leis Gabinia, Apuleia, Varia, Cornelia e afinal a Lei Fulia Majestatis, celeberrima entre todas, decretada por Julio Cesar. Pothier, Pand. Com. ad XII Tab. 
Parece á primeira vista um paradoxo que na Republica Romana se hajam feito leis, em que a palavra majestade entrasse como nota caracteristica dessa disposição politico penal. A difficuldade se resolve em conhecer o conceito do vocabulo. A lei Fulía $M a$ jestatis, como as outras celebres que antecederam, não encerrava, ou, antes, não encerra, no seu conceito juridico, as idéas do Direito Publico moderno. Encerra, em verdade, o que se concebia certo, justo, juridico, necessario naquelles tempos.

Cicero, ao mesmo tempo advogado inexcedivel philosopho e politico, vulto de primeira grandeza na ordem litteraria de seu tempo, dá-nos de sua propria bocca a concepção philosophica desse direito cunsagrado já em varios textos. Ouçamol-o:

$$
\begin{aligned}
& \text { "Majestas residet 'proprie in } \\
& \text { «populo romano. E' no povo ro. } \\
& \text { «mano que reside a majestade.» } \\
& \text { 'Lib. } 2 \text {, de invent. }
\end{aligned}
$$

A soberania, ou, antes, o imperio dos consules cedeu logar ao imperio dos imperadores. Esta mutação da ordem politica concorreu grandemente para a mutação na ordem das idéas. $\mathrm{E}$ antes que Constantino, e, muito mais que elle, o grandissimo Theodosio abrandassem por suas ordenanças a dureza das leis de lesa-majestade, ja o curso dos primeiros seculos imperiaes havia operado a metamorphose do conceito verdadeiro de Cicero.

A majestade conservára o nome, porem mudára de residencia: não residia mais no povo, mas na pessoa do imperador. A regra do direito politico enunciada por Ulpiano já traduz a radical mutação: "Quod "principi placuit, legis habet vigorem. "A vontade do "principe tem força de lei». 
Uma serie de factos e factos estrondosos, como são em geral os eventos da ordem politica, não podia deixar de influir na mente dos pensadores e dos tratadistas.

A successão do imperante, que era o facto de maior momento e culminancia, não obedecia a um criterio.

Ora o braço assassino de um pretoriano, ora o veneno nas taças do banquete, ora a vontade de uma legião esfaimada, ás vezes a vontade serena do imperador moribundo, ás mais das vezes o suffragio dos chefes militares, e ainda ás vezes a necessidade de um general que excellesse tão só pelas virtudes guerreiras, eis os modos varios da successão soberana, eis como se extinguia e renascia o supremo poder, no decurso de muitos seculos, em um povo que incarnou em si a civilisação antiga, de que herdamos os monumentòs da razão juridica.

Desappareceu a velha plebe e o plebiscito; desappareceu a representação e o brio do Senado e o valor do senatus-consulto: desappareceu o tribuno e o seu veto. Permaneceu a multidão, o ignobil vulgo, o povo amorpho, a mescla anonyma, incapaz de uma manifestação de vontade; permaneceu um corpo de senadores, que mal servia para enfeite do Imperio e que bem servia pará adherir a todos os prefeitos. No meio, porem, do cahos politico, uma cousa sempre sobrenadou: quem tinha em si a corôa imperial, esse era o que fazia e desfazia o direito. Evaporou-se do povo toda a idéa de majestade; esta radicou-se e engrandeceu na pessoa dos Imperadores.

\section{V}

Antes da codificação justiniana, já o imperio do Occidente se despedaçava em ruinas sob o peso dos 
barbaros. O imperio de Oriente, todavia, com sua lingua grega e seus vicios proverbiaes, havia de durar por muitos seculos. Porem, tão completamente a politica bysantina se desirmanou dos interesses do Occidente, que parece uma escandalosa mentira essa verdade, attestada por monumentos de toda a especie. O Occidente não foi dahi em diante uma unidade em cousa alguma, porem chamou-se assim tudo que não era territorio do imperio bysantino e não obedecia a suas leis. Surgiram novos reinos e imperios de nova gente e constituiram-se fortissimas dynastias, que tinham o destino de atravessar os seculos. Correrain mais de seis seculos, tempo sufficiente para se elaborarem novas ideas, novas fórmas, ou novas figuras no direito publico. O grande manancial das leis romanas estava sepultado; e os Estados, que irromperam dos destroços de Roma, tinham para si leis dos barbaros, domesticados pelo christianismo, com mistura de fragmentos dos Codigos Theodosiano e Hermogeniano.

So no seculo XII o rei Lothario levantou do pó de muitas eras a collecção das Pandectas, achada no assedio de Amalfi. Eis o facto com que accendeu IRnERIo os novos clarões do Occidente, dando logar a que irradiassem para nós os padrões juridicos do Imperio romano, commentados, ampliados, modificados pela philosophia dos jurisconsultos medievaes.

Os textos romanos se conservaram, mas o Direito Publico se affirmava de accôrdo com os tempos: e as monarchias absolutas davam de si as tantas grandezas que formam boa parte do glorioso patrimonio de nossos maiores e fazem a inveja das democracias modernas.

Assim é que Affonso V, o Africano, ao fazer a collectanea do seu livro V, diz, no titulo segundo, 
que essa era a lei de Dom Affonso, o Segundo, de louvada memoria. E no $\S 4$ deste titulo, antes de enumerar os casos-crimes de lesa-majestade (aliás os mesmos que traz a collecção philippina), assim se exprime, começando por dar o valor das palavras: «Lesa«majestade, em latim, tanto quer dizer em linguagem, "como erro de treiçom, que o homem faz contra a pessoa «de El-Rey. . »

Notemos que Affonso II é do seculo XIII, e Affonso, o Africano, é do seculo XV.

\section{VI}

Para concluir: $\mathrm{O}$ instituto, ou capitulo de Direito Politico-criminal, chamado majestade, é palavra vazia de senso no direito hodierno.

Não pode haver crime contra a majestade, porque ella, sendo ja absoleta ao tempo da nossa independencia, depois della ficou perempta expressamente.

A lei philippina, que negava menagem aos crimes que feriam a majestade, não pode servir de norma a applicações modernas de leis que visam a seguridade da Republica. Poderia servir de simile, si ainda hoje existisse alguma coisa que se pudesse approximar do conceito do orador romano.

A majestade na Republica Brasileira nem existio, nem existe: falta-lhe a pessôa em quem se incarne. Não pode existir aquella majestade, congrada no Direito Regio, porque não ha rei; não pode existir a da lei Fulia Majestatis, porque não ha o culto do povo. Querer, portanto, o meritissimo juiz animar o seu despacho com a invocação de um estatuto que caducou e esvaeceu, é tanto como escrever a sentença com o-sangue de um cadaver. 
O tempo, ajudado ou desajudado dos philosophos, opera mutações radicaes: converte e reverte instituições em toda especie de actividade humana. E muitas vezes os jurisconsultos, arrebatados nas ondas e impellidos por ellas, cuidam, em seu gabinete e no orgulho de suas obras, que elles é que traçam ás sociedades o caminho das reformações!

As epocas de 1822 e I 824 fizeram para nós uma monarchia democratica, isto é, uma nação, cujo governo era repartido em quatro poderes, solemnemente affirmados como delegações da nação (Const. IMP., arts. IO, I I, I 2).

Perimio-se a majestade. Que é que a extinguio? Dizem uns que foi a sciencia dos philosophos; outros, que foi a sabedoria dos jurisconsultos; outros affirmam que toi o anonymo progresso, e ha tambem quem reclame para o caso a foice roçadora da Republica, como a instituição que mais direitos tem matado e mais tem calcado a majestade de todas as coisas.

O impetrante sabia que estava investindo com braço imbelle contra as Columnas de Hercules.

O meritissimo juiz continuaria talvez a indeferir a pretensão de menagem: todavia, não era licito ao impetrante consentir, sem respeitoso protesto, que falasse em leis de lesa-majestade um tão alto representante da justiça brasileira. $O$ meritissimo juiz falou em nome do Poder Judiciario, que é um dos ramos do nosso Poder Politico, e apegou-se ás leis antigas que defendiam a majestade. Ha ahi incongruencia clamorosa.

O Poder Politico actual gaba-se de estar fundado sobre o levante de I 5 de: Novembro. Esse sim: foi um attentado ruidoso de lesa-majestade. Porque, si houve no seculo passado quem pôde incarnar todos 
os conceitos ou todas as qualidades de ordem moral e de ordem politica, cujo complexo se traduz pela palavra majestade, foi o Senhor D. Pedro II, de immorredoira memoria.

Que auctoridade tem hoje o poder judiciario da Republica para falar em crimes de lesa-majestade?!

E', quando menos, ignorar o texto do Evangelista:-Qui sine peccato est vestrum, primum in illam lapidemı mittat. Só pode apedrejar a adultera, quem for puro do peccado de adulterio.

Dezembro de 1902.

Dr. Raphael Corrêa da Silva. 